\title{
An Evaluation of Data Collected by Middle School and College-Level Students in Stream Channel Geomorphic Assessment
}

\author{
Martin D. Lafrenz \\ Department of Geography, Portland State University, P.O. Box 751-GEOG, Portland, OR 97207-0751, USA \\ Correspondence should be addressed to Martin D. Lafrenz; lafrenz@pdx.edu
}

Received 31 May 2013; Revised 27 October 2013; Accepted 31 October 2013

Academic Editor: Siyue Li

Copyright (C) 2013 Martin D. Lafrenz. This is an open access article distributed under the Creative Commons Attribution License, which permits unrestricted use, distribution, and reproduction in any medium, provided the original work is properly cited.

\begin{abstract}
This project tested the accuracy and repeatability of geomorphic stream channel assessments conducted by two different middle school classes from the Walt Morey Middle School in Troutdale, OR and college students from Portland State University in Portland, OR. Each group surveyed the same three cross-sections in Fairview Creek, a tributary to the Lower Columbia River, in order to assess stream channel geometry, discharge, composition of the bed material, and water quality. The three student groups were all able to accurately document the stream channel geometry, including stream width and mean depth, indicating that these data can be successfully collected by volunteers of various ages. However, stream velocity obtained using the float method was consistently overestimated leading to a biased calculation of discharge, and the low precision of the measurements did not allow for a correction of the bias. The median particle size of the bed material determined by a pebble count was also overestimated by each group, but the low precision also negated the possibility of correcting the estimate. The stored fine sediment in the bed was underestimated by each group and again with low precision. The temperature, $\mathrm{pH}$, and conductivity measured with a calibrated multimeter were accurate and precise for all groups.
\end{abstract}

\section{Introduction}

Watershed-scale models are increasingly being used to assist researchers and managers with determining the flux of sediment and nutrients between land and stream channels $[1,2]$. Models are useful as the sheer magnitude of stream channel degradation, particularly in urban areas [3], by far exceeds the management resources required to assess and monitor changes in every impaired stream reach. Most sediment models use landscape variables, which can be derived from a Geographic Information System (GIS), to predict sediment delivery to a stream, and a few sediment models have incorporated in-channel sediment transport equations to further refine the ultimate sediment delivery volumes [4]. However, it is problematic to model the sediment contribution of the stream channel itself at the watershed scale because the inherent spatial and temporal heterogeneity of in-channel stored sediment is difficult to monitor remotely. Given that stream banks have been shown to contribute $80 \%$
[5] to $96 \%$ [6] of the total instream sediment load, fluvial geomorphologists and land resource managers have come to realize the pressing need for in situ gathered stream channel information in order to assess the impact of various land use practices on aquatic habitat and stream condition [7]. Further, much of this information will have to come from locally led volunteer groups in order to fill in the massive data gaps. The Federal Interagency Stream Restoration Working Group recognized this dilemma and created resources to educate the public and to provide guidance about stream corridor restoration [8]. However, we have yet to adequately demonstrate both the usefulness and the repeatability of these volunteer efforts with respect to stream channel geomorphic assessment.

The scientific value of data collected by community volunteers has been assessed on projects that monitor physical and chemical water quality parameters, such as clarity, $\mathrm{pH}$, nutrients [9-11], and the stream biological condition based on benthic macroinvertebrate assemblages [12-14]. 


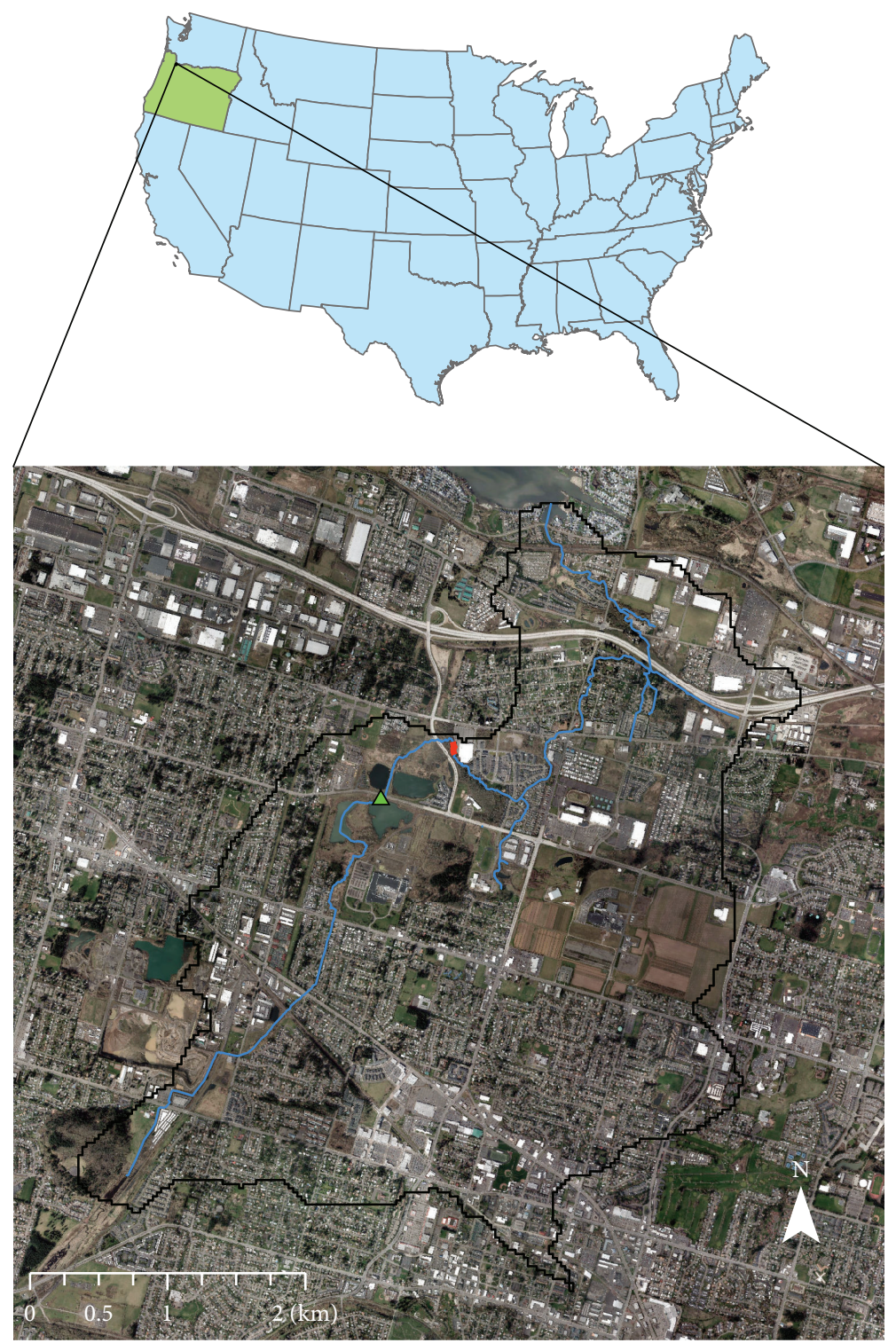

Study reach

$\triangle$ USGS gage

Figure 1: Fairview Creek watershed in east Multnomah County, OR.

These data are generally comparable to results gathered by professionals provided the volunteers have received adequate training and follow strict protocols [15]. Although there are several protocols describing how volunteers can survey the geomorphic condition of a stream channel [16-18], these data have not been evaluated in the same manner as volunteer-collected water quality data. In this research, I report the usefulness and repeatability of stream channel geomorphic data collected by both middle school and college level students in Fairview Creek, a tributary to the Lower Columbia River in Troutdale, OR (Figure 1), and I suggest modifications to existing protocols that may increase the utility of data collected in future volunteer efforts.
Geomorphologists recognize that small, low-order streams like Fairview Creek tend to be much more closely linked to the land surfaces of their contributing areas than larger, higher-order streams [19]. However, little is known about most small tributary streams because the limited resources for assessment severely constrain the spatial and temporal frequency of stream monitoring. Small streams are important for their areal extent; they directly drain $70 \%$ to $80 \%$ of the land area for most regions, and as essential sites of coupling between contributing land areas and stream channels, they are places where the effects of human land uses are readily transmitted to stream channels [20]. Small streams are often biologically important as sites of endemism [21], and their catchments are important areas 
of groundwater recharge [22]. The relatively short transport distances found in small catchments can deliver water and sediment rapidly to stream channels; however, low actual discharges from small contributing areas may not be capable of quickly mobilizing large amounts of accumulated sediment. Hence, the size and shape of small stream channels can be readily affected by disturbances in their contributing areas, and changes in channel morphology may persist long after the actual disturbance events [23].

Many small urban streams, like Fairview Creek, have been highly impacted by development. The north-flowing $8 \mathrm{~km}$ long Fairview Creek, in east Multnomah County, OR, drains $28 \mathrm{~km}^{2}$ of residential, agricultural, commercial, and industrial lands (Figure 1). It heads southeast of Grant Butte in Gresham, OR, and flows through forested, rural, and urban lands, as well as several natural and two constructed wetlands, before entering Fairview Lake near the Columbia Slough. In the last few decades, flooding and accelerated erosion have severely impacted portions of the creek, restricted anadromous fish passage, and negatively affected native fish populations. Restoration activities currently underway include invasive species removal in the creek's headwaters, native tree plantings in several locations, and education outreach on tree planting to homeowners with property in the riparian areas of the upper watershed. A reach-scale visual assessment of the stream channel condition was done on Fairview Creek in 1982 [24] prior to most of the development in this watershed. Since that time there have been no further reports on the geomorphology of Fairview Creek until the research reported here.

\section{Methods}

In order to assess the accuracy and repeatability of a stream geomorphic assessment done by different types of volunteers, the same three cross-sections along a $100 \mathrm{~m}$ reach of Fairview creek were surveyed by the author, a group of Portland State University Geography undergraduate students enrolled in Geography 420 "Field Methods in Physical Geography" (PSU420, 20 students), and two different sixth grade classes from Walt Morey Middle School (Moreyl, 30 students; Morey2, 30 students). Each group conducted a geomorphic assessment that included measuring stream channel width and depth, the size and nature of the streambed material, stream discharge, and several water quality parameters. All four stream survey trips were done within a three-week period of time, in late spring and during low flow conditions. Prior to the surveys, the author visited each class and gave a 30-minute presentation on fluvial geomorphology and showed maps of the watershed and stream reach location.

The author, along with a graduate research assistant, located a suitable reach for the surveys and chose three crosssections to survey, including a riffle, run, and pool. Each cross-section was monumented by installing a 0.61 -meterlong, capped, and marked piece rebar nearly flush with the ground surface on the left bank of each cross-section location. The author and graduate assistant then surveyed each crosssection to establish the reference values using the exact same standard methods and data sheets that would be used by each subsequent group to determine channel dimensions [25], the properties of the stream bed sediment [26, 27], discharge [25], and stream water temperature, $\mathrm{pH}$, and conductivity using a portable multimeter.

Upon arrival at the site each class was organized into three groups; the college students were unsupervised while each sixth grade group had a parent volunteer. Each group was given hip waders, data sheets, and a bucket of equipment consisting of a clipboard, calculator, two tent stakes, $30 \mathrm{~m}$ nylon tape, mason's string, line level, stadia rod, stopwatch, gravelometer, three $250 \mathrm{~mL}$ plastic bottles, metric ruler, and a 5-gallon bucket with the bottom cut away. The entire class was given instructions on using the gravelometer for a pebble count, how to read a stadia rod, and how to take notes. After several demonstrations each group was led to the assigned cross-section and proceeded to conduct the steam channel survey.

2.1. Channel Dimensions. To measure the channel dimensions, each survey group placed a metal stake next to the cross-section monument on the left bank and another stake on the right bank creating a cross-section that was perpendicular to the flow of the water. The group then strung the nylon tape between the stakes as level as possible. Using the mason's string and line level, the group established a level line between the stakes, above the tape, and used the ruler to ensure that the tape was tightly strung and level; the group was instructed to periodically ensure that the tape was still level and not sagging by measuring relative to the leveled line. Beginning at the position along the tape denoting the left edge of the stream, the group noted the horizontal location to the nearest centimeter and measured the water depth at this position. A student then moved the $\operatorname{rod} 10 \mathrm{~cm}$ along the tape and determined the water depth at this position. This process was repeated until reaching the right edge of the stream. The stream cross-sectional area was then calculated as the product of stream width and the average depth of the water.

2.2. Streambed Materials. The students next used two methods to determine the nature of the streambed material. First, they conducted a modified Wolman pebble count [26] to measure the distribution of particles greater than $2 \mathrm{~mm}$ in size using a gravelometer; this device is an aluminum template with punched, square holes and marks along its edge that allow the user to measure particle size in standard phi sizes ranging from $2 \mathrm{~mm}$ to $256 \mathrm{~mm}$. With this method the students walked heel-to-toe back and forth across the stream measuring the first particle touched just in front of their foot; each group was instructed to collect at least 100 measurements and to walk all the way across the stream on the last trip rather than stopping exactly at 100 measurements. The median particle size $\left(\mathrm{d}_{50}\right)$ was calculated by log-linear interpolation, after the field trip, using a spreadsheet developed by the author.

The second streambed characterization was done using a modified quorer technique [27] to determine the amount of fine material $(<2 \mathrm{~mm})$ stored in the streambed. Each group 
had a student randomly selecting a spot near the left bank and push a bottomless 5-gallon bucket into the streambed until reaching a depth where the particle size changed abruptly; the student then measured the depth of the water and the depth of fine sediment, stirred the sediment and water into a slurry using a tent stake, and collected a sample of the slurry using the $250 \mathrm{~mL}$ bottle. The process was repeated in the center of the stream and near the right bank for a total of three samples per cross-section. Back in the classroom, each sample was poured into an Imhoff cone; the volume of the slurry sample was recorded, and the volume of the sampled sediment was recorded after being allowed to settle for 48 hours. The volume of stored fine material was calculated by comparing the ratio of sample volume relative to the volume of the slurry (water depth plus sediment depth times bucket area); the mean stored volume of sediment in milliliters was then divided by the area of the bucket so as to comparatively assess milliliters of stored sediment per square meter of streambed among the surveyed cross-sections.

2.3. Stream Discharge. Each group determined stream discharge using the float method [25]. The nylon tape was laid along the left bank for a distance of $5 \mathrm{~m}$. A student then selected five small sticks; groups were instructed to visually divide the stream into five equal sections and to obtain float times for each of those sections. The time needed for each stick to float the $5 \mathrm{~m}$ of stream was noted, and the average time was calculated. This mean float time was multiplied by 0.85 to account for the effect of bed roughness on overall stream velocity [25]. This adjusted velocity was multiplied by the stream cross-sectional area to obtain discharge in cubic meters per second; given the relatively low discharge of this small stream, these results were then converted to liters per second to obtain values greater than one. Finally, students were instructed to directly sample the stream water temperature, $\mathrm{pH}$, and conductivity using an ExTech EC500 meter.

2.4. Expected Outcomes. Stream width, depth, and velocity will be different for each particular class and as well as for the author given that the surveys took place on different days; hence, the cross-sectional areas and discharge values will not be directly comparable among groups. However, the relative values are comparable; for instance, the riffle should have a smaller mean depth and higher velocity than those of the run and the pool [28]. Because no large floods occurred during the several weeks spanning all four surveys, the bed material measurements are directly comparable among groups for each cross-section. The accuracy of each discharge measurement is assessed by comparing each group's result to an adjusted 30-minute instantaneous measurement from a USGS stream gage (14211814) located upstream of the sample reach. No tributaries enter Fairview Creek between the cross-sections, which are also spaced within 100 meters of each other. Thus, each group's discharge value from a particular class should be the same, and these results will be used to assess the repeatability of measurement by a particular class. In addition, the water quality data collected with the multimeter should be similar within each class but may vary among the classes.

\section{Results and Discussion}

The three surveyed cross-sections include the riffle, the run, and the pool. Each of the four groups was in agreement on the relative width of each cross-section with the riffle being the widest followed by the run and the pool (Table 1). Stream channels typical widen and scour following urbanization because of the increased peak flow associated with impervious surfaces [3]. The large particles in the bed at the riffle cross-section have encouraged widening over scour leading to its relatively larger dimension. All four survey groups also correctly measured the riffle as having the lowest average depth (Table 1); in fact, three of the groups obtained exactly $0.19 \mathrm{~m}$ for the mean depth. The variability in width measurements was higher than in the depth measurements although the largest range in measured width was only $0.31 \mathrm{~m}$ for the run.

With increasing discharge stream width will increase more rapidly than average depth [28], and this is mostly borne out with these data. However, discharge was lower on the day Moreyl conducted the survey than when Morey2 conducted their survey, and yet the Moreyl riffle and run stream widths are slightly higher than the Morey2 results. The discharge values were more similar on the days that Morey2 and PSU420 conducted surveys and each class stream width is quite similar. This error by Moreyl could have resulted from not keeping the tape perfectly level producing a slope distance rather than a horizontal distance, not stringing the tape exactly perpendicular to the flow of the stream, or misreading where the tape lines up with the edge of the stream. It is difficult to achieve centimeter precision when attempting to read a tape strung a meter above the water surface, and it appears that many groups simply rounded to the nearest decimeter. Using decimeter precision and taking into account tape errors, these width values are generally in good agreement with the expected results in that they are slightly higher than the author's values, which were recorded on the day with the lowest discharge.

Average depth values similarly increase slightly with increasing discharge and are all, again, greater than the author's results. As expected, the pool had the greatest measured depth value for each group except PSU420. However, the pool depth is only slightly deeper than the run, which is unexpected. This may be a function of the pool accumulating fine sediment during this time of low flows. Depth measurements are more precise than the width measurements because each group used a stadia rod to measure depth and could exactly read where the water surface intersected the rod. Errors with this technique arise from misreading the stadia rod, which surprisingly did not appear to be an issue, and from the placement of the rod. Students were told to place the rod on the streambed exactly at the next $0.10 \mathrm{~m}$ increment regardless of whether there was a rock at that position; some students were observed avoiding large rocks, which is the likely source of variation with this measurement. 
TABLE 1: Stream channel geometry and discharge results from the upstream USGS gage at the time of each survey.

\begin{tabular}{lcccc}
\hline & Width $(\mathrm{m})$ & Mean depth $(\mathrm{m})$ & Cross-sectional area $\left(\mathrm{m}^{3}\right)$ & Discharge $(\mathrm{l} / \mathrm{s})$ \\
\hline Author: riffle & 3.46 & 0.19 & 0.66 & 0.86 \\
Author: run & 3.32 & 0.26 & 0.88 & 130 \\
Author: pool & 3.27 & 0.27 & 0.69 & 130 \\
Morey1: riffle & 3.65 & 0.19 & 1.01 & 153 \\
Morey1: run & 3.60 & 0.28 & 0.99 & 153 \\
Morey1: pool & 3.20 & 0.31 & 0.79 & 1.05 \\
Morey2: riffle & 3.60 & 0.22 & 1.02 & 183 \\
Morey2: run & 3.50 & 0.30 & 0.70 & 187 \\
Morey2: pool & 3.30 & 0.31 & 1.13 & 201 \\
PSU420: riffle & 3.70 & 0.19 & 0.92 & 201 \\
PSU420: run & 3.63 & 0.31 & 0.28 & \\
PSU420: pool & 3.30 & & & 201 \\
\hline
\end{tabular}

TABLE 2: Stream channel measurements for discharge calculations and comparisons among cross-sections.

\begin{tabular}{|c|c|c|c|c|c|}
\hline & $\begin{array}{l}\text { Cross-sectional } \\
\text { area }\left(\mathrm{m}^{3}\right)\end{array}$ & $\begin{array}{l}\text { Stream velocity } \\
(\mathrm{m} / \mathrm{s})\end{array}$ & $\begin{array}{c}\text { Calculated } \\
\text { discharge }(1 / \mathrm{s})\end{array}$ & $\begin{array}{l}\text { Expected discharge } \\
\text { from USGS gage }(1 / \mathrm{s})\end{array}$ & $\begin{array}{c}\text { Calculated-expected } \\
(1 / \mathrm{s})\end{array}$ \\
\hline Author: riffle & 0.66 & 0.23 & 152 & 150 & 2 \\
\hline Author: run & 0.86 & 0.18 & 155 & 150 & 5 \\
\hline Author: pool & 0.88 & 0.18 & 158 & 150 & 8 \\
\hline Moreyl: riffle & 0.69 & 0.40 & 276 & 176 & 100 \\
\hline Moreyl: run & 1.01 & 0.23 & 232 & 176 & 56 \\
\hline Moreyl: pool & 0.99 & 0.24 & 238 & 176 & 62 \\
\hline Morey2: riffle & 0.79 & 0.33 & 261 & 215 & 46 \\
\hline Morey2: run & 1.05 & 0.22 & 231 & 215 & 16 \\
\hline Morey2: pool & 1.02 & 0.23 & 235 & 215 & 20 \\
\hline PSU420: riffle & 0.70 & 0.39 & 273 & 232 & 41 \\
\hline PSU420: run & 1.13 & 0.23 & 260 & 232 & 28 \\
\hline PSU420: pool & 0.92 & 0.29 & 267 & 232 & 35 \\
\hline
\end{tabular}

The reach location drains an $8.4 \mathrm{~km}^{2}$ area while the USGS gage, located upstream, drains $7.8 \mathrm{~km}^{2}$ [29]; the ratio of drainage basin size to discharge was used to adjust the readings from the gage to the expected discharge at the survey reach for each day of surveys (Table 2). The measured discharge at each cross-section during each individual day of surveying should be the same and any variation represents an error in measurement leading to reduced precision. The author had the smallest range in discharge followed by the college students (PSU420) and Morey2 then Moreyl (Table 2 and Figure 2). Discharge is product of cross-sectional area and velocity; as such the errors discussed in width and depth measurements will also affect the discharge results. However, as noted, these groups had relatively accurate cross-section measurements with fairly good precision. In contrast, the velocity measurements are more highly varied, particularly for measurements taken at the riffle cross-section (Table 2). For instance, the author's riffle velocity measurement was $5 \mathrm{l} / \mathrm{s}$ higher than the pool measurement whereas the riffle velocity for each student group was at least $10 \mathrm{l} / \mathrm{s}$ higher than the pool result.
An issue with using the float method for determining stream velocity lies in obtaining floats from different portions of the stream when the stream surface has highly varied velocities. In a riffle, it is often difficult to get a stick to float downstream anywhere other than where the surface velocity is highest; runs and pools have a more uniform surface velocity allowing one to actually obtain a successful float in any portion of the stream. The author attempted numerous floats at the riffle in order to obtain five values that were equally spaced across the stream surface; hence, the mean velocity is relatively lower, by a wide margin, than the results obtained by the other three groups. The more uniform surface velocity in the run and the pool led to higher precision for velocity measurement among these cross-sections.

The overestimation of stream velocity at the riffle crosssection by the student groups produced much higher discharge values at the riffle than at the other two cross-sections. In contrast, the author calculated the highest discharge at the pool (Table 2). As mentioned, the discharge values from each day should be the same. All groups had quite similar discharge measurements for the run and the pool, because 


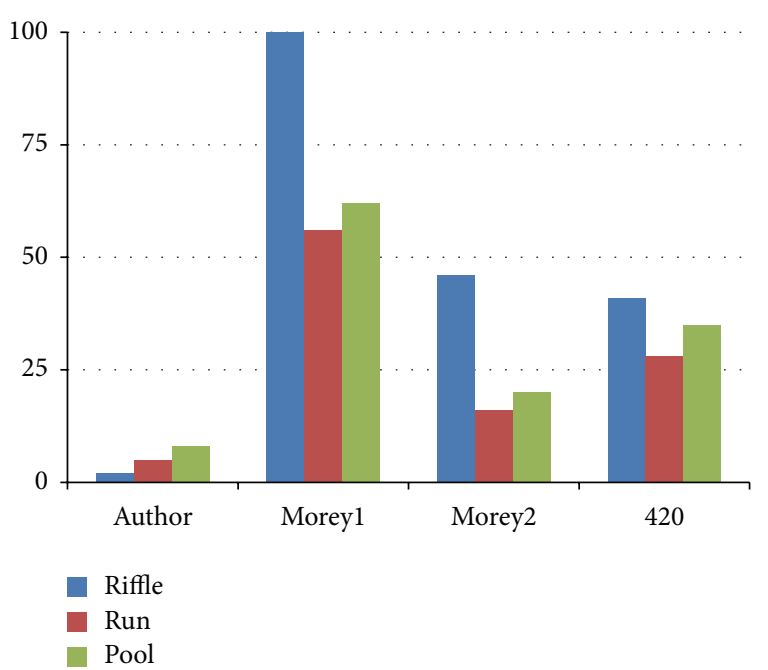

FIGURE 2: Difference between the measured discharge (1/s) by group for each cross-section and the expected discharge relative to an upstream USGS stream gage value that has been adjusted based on the drainage basin area at the study reach. The difference is a measure of accuracy and the closeness of values by group is a measure of precision.

each location had relatively similar cross-sectional areas and less complex surface velocities. In addition, all groups found the pool to have higher discharge than that of the run as each group measured a relatively higher velocity in the pool. This bias is also attributable to using the float method for velocity measurement. This overestimate in pools results from assuming all water in the pool is moving downslope when in fact there is negative velocity in the residual pool depth upstream of the riffle crest that is not measured with the float method.

The accuracy of each group's calculated discharge can be evaluated by comparing it to the expected discharge values obtained from the USGS gage, which have been adjusted to the area of the drainage basin at the study reach (Table 2). The measured discharge for each group and for all cross-sections was greater than the expected discharge, which could indicate that the method for determining the adjusted discharge by ratio of basin size underestimated actual discharge. However, the author's discharge results are only slightly larger than expected, and the pattern matches the probable overestimation of stream velocity; the difference between measure discharge and expected discharge is lowest at the riffle where it appears that the float method worked well and highest at the pool where negative velocity at depth is not captured by the float method (Figure 2). Measured discharge by the student groups all showed the same pattern. The riffle measurement was vastly overestimated, and the pool showed the next highest overestimate, which was actually not much higher than the run values. The overestimation of stream velocity at the riffle cross-section led directly to the error in determining accurate discharge for the student groups indicating that the float method may not be a useful technique for volunteers to use when surveying riffles. The pattern of

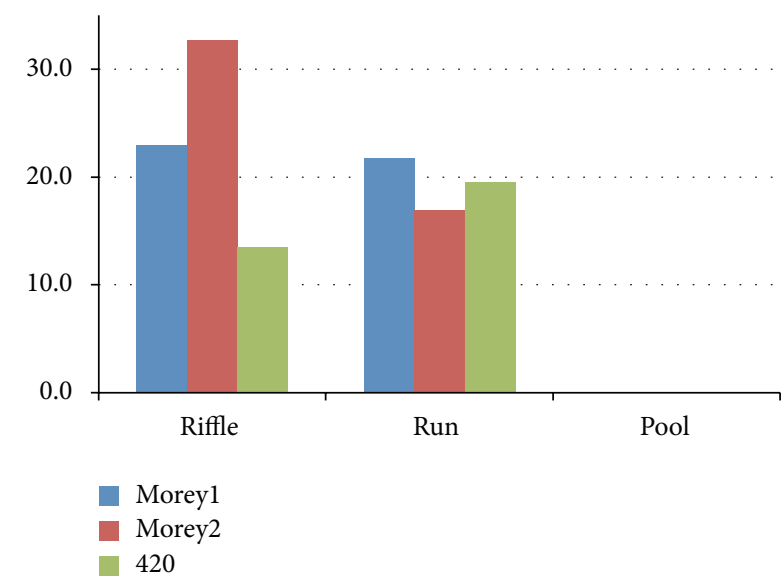

FIGURE 3: Difference between the measured median particle sizes $(\mathrm{mm})$ by cross-section for each group compared to the author's values. The difference is a measure of accuracy and the closeness of values by cross-section is a measure of precision. Note that there was no difference among the groups for the pool.

pool error being higher than that of run error for all four groups reinforces the notion that the float method is also illsuited to velocity measurement in pools.

The bed material assessments for median particle size $\left(\mathrm{d}_{50}\right)$ and the amount of stored sediment will produce different results for each cross-section given the nature of sediment transport in streams. The median particle size is largely a function of stream velocity and therefore should be highest in the riffle, lowest in the pool, and transitional in the run. The characteristics of the material will have changed little during the less than bankfull conditions that spanned this study. This allows for a direct comparison of each group by cross-section to the author's results in order to assess accuracy and among each group's cross-sections to evaluate precision. Each student group overestimated the median particle size for the riffle and the run (Table 3 and Figure 3). Overestimation is common when using the pebble count method as people tend to ignore small particles, such as gravel, in favor of larger particles [30].

In addition, it appears that some groups may have double counted very large particles that spanned more than one footstep when walking heel-to-toe, which would also inflate the estimate of median particle size. The pattern for each group matches the expectation of descending particle size measurements from riffle to run to pool (Table 3). However, the magnitude of error had no pattern with Moreyl equally overestimating the riffle and run, Morey 2 more highly overestimating the riffle, and PSU420 more greatly exaggerating the run (Figure 3). Each group recorded exactly the same median particle size for the pool of $2.0 \mathrm{~mm}$. At the time of the surveys the pool was aggrading and filling with fine sediment that likely was being generated from upstream urbanization (Figure 1). Coarse material was present in this cross-section, but each group recorded more than 60 particles less than $2.0 \mathrm{~mm}$ leading to this minimum value for median particle size. In sum, it can be concluded that unless the bed material 
TABLE 3: Results from streambed material assessments and comparisons by cross-sections.

\begin{tabular}{lcccc}
\hline & $\mathrm{d} 50(\mathrm{~mm})$ & Difference from author $(\mathrm{mm})$ & Bed fines $\left(\mathrm{ml} / \mathrm{m}^{2}\right)$ & Difference from author $\left(\mathrm{ml} / \mathrm{m}^{2}\right)$ \\
\hline Author: riffle & 16.1 & - & 10325 & - \\
Author: run & 4.4 & - & 38880 & - \\
Author: pool & 2.0 & - & 53766 & -7188 \\
Morey1: riffle & 39.0 & 22.9 & 3137 & -24280 \\
Morey1: run & 26.1 & 21.7 & 14600 & -38146 \\
Morey1: pool & 2.0 & 0.0 & 15620 & -8136 \\
Morey2: riffle & 48.8 & 32.7 & 2189 & -25540 \\
Morey2: run & 21.3 & 16.9 & 13340 & -31193 \\
Morey2: pool & 2.0 & 0.0 & 22573 & -8489 \\
PSU420: riffle & 29.6 & 13.5 & 1836 & -10980 \\
PSU420: run & 23.9 & 19.5 & 27900 & -11386 \\
PSU420: pool & 2.0 & 0.0 & 42380 & \\
\hline
\end{tabular}

TABLE 4: Water quality data from all cross-sections.

\begin{tabular}{lccc}
\hline & Temperature (C) & $\mathrm{pH}$ & $\begin{array}{c}\text { Conductivity } \\
(\mu \mathrm{S} / \mathrm{cm})\end{array}$ \\
\hline Author: riffle & 19.6 & 7.83 & 200 \\
Author: run & 20.3 & 7.70 & 201 \\
Author: pool & 19.0 & 8.17 & 198 \\
Morey1: riffle & 19.4 & 8.02 & 260 \\
Morey1: run & 20.1 & 8.07 & 223 \\
Morey1: pool & 17.8 & 8.10 & 251 \\
Morey2: riffle & 18.2 & 8.40 & 241 \\
Morey2: run & 18.3 & 8.24 & 220 \\
Morey2: pool & 17.8 & 8.25 & 216 \\
PSU420: riffle & 17.2 & 7.80 & 203 \\
PSU420: run & 16.3 & 7.82 & 204 \\
PSU420: pool & 16.3 & 7.80 & 197 \\
\hline
\end{tabular}

is fairly homogenous this method has both low accuracy that is consistently biased to overestimation and low precision with no detectable bias.

In direct contrast to the median particle size results, the stored sediment was consistently underestimated by each student group (Table 3). Stored sediment will have the greatest accumulation in low energy environments; hence, it should be highest in pools, transitional in runs, and lowest in riffles. This pattern holds true for all four groups (Table 3) meaning the data are consistently biased; however, the difference between each group's values and the author's results does not show any pattern and has low precision (Figure 3 ). In comparing the group's results to each other the middle school students obtained nearly identical results although both were much lower than the author's values. The college students' results were more comparable to the author's with the exception of the riffle. It is not surprising that the riffle values were low among the student groups as it is difficult to push the bucket into the substrate of the coarse-bottomed riffle. Further, the middle school students were more hesitant to deeply stir the sediment in the manner necessary to suspend all of the fines into a slurry. As such, these data are consistently underestimated by the student groups in a predictable pattern that matches the geomorphology of the stream, but the method appears to have low repeatability among the groups.

Steam temperature, $\mathrm{pH}$, and conductivity as measured with a multimeter showed the highest accuracy and precision for all groups (Table 4). This is not particularly surprising as the results are more a function of meter capability than the user ability provided the meter is properly calibrated and the stream is sampled in moving water. The variability in these data is likely a function of the latter. The pool usually had the highest $\mathrm{pH}$ indicative of slower moving water with submerged aquatic vegetation that tends to increase $\mathrm{pH}$ through photosynthesis, while the riffle mostly had the highest conductivity given the higher velocities capable of suspending more material in the water column. Nevertheless, these water quality parameters were much more successfully assessed by the students than the geomorphic data, which is likely why so little volunteer time is devoted to geomorphic assessments relative to water quality monitoring.

\section{Conclusions}

The number of impaired streams in need of assessment and monitoring continues to exceed the resources of resource managers. Watershed-scale modeling shows promise for monitoring water quality parameters provided there is adequate data; unfortunately, information on the geomorphic condition of stream channels, which would greatly improve the accuracy of watershed models, is geographically limited and infrequently collected. This project sought to assess whether community volunteers, including middle school students, adult volunteers, and college-level students, could collect scientifically useful stream channel data in a repeatable manner. The pebble count and quorer methods for assessing bed material were not particularly accurate although each was consistently biased; unfortunately, the precision among the student groups was low making it difficult to correct for any bias. Stream discharge measurements were also consistently overestimated because of issues with the float method for 
measuring stream velocity; however, these measurements also showed low precision that could not be corrected. If funds are available these data could be greatly improved by use of a velocimeter; alternatively, future researchers could build transparent velocity head rods (TVHR), which measure the velocity head of water striking the rod in order to obtain stream velocity [31]. The stream channel geometry measurements of width and mean depth showed the greatest promise from the geomorphic assessment. The values were fairly accurate and consistent among the groups. Thus, it is likely that these data could be easily and accurately collected by many types of volunteers for use in watershed modeling. As noted, bank failure can contribute a large proportion of the sediment load to a stream. Hence, monitoring stream width can inform managers about possible sources of sediment, and changes in mean depth can indicate scour or storage of sediment in a particular reach.

A shortcoming of this project is that the student groups measured only the stream width when the bankfull width and depth would have been more informative. In future projects, managers should adjust the protocols described here and have the volunteers begin at the monument on the left bank and measure the height of the leveled string. When plotting these data the bankfull position would likely be apparent as an inflection point on the cross-section graph, which could be quickly verified by a field visit; the area between the string and the bankfull height could then be subtracted to obtain the bankfull cross-section parameters.

The water quality data collected with the multimeter was the most accurate and repeatable and should certainly be incorporated into any watershed monitoring effort. It is unfortunate that the bed material data is so difficult to assess by volunteers. However, it was also the most time consuming activity. Hence, each group could have surveyed the channel dimensions of two additional cross-sections in the time it took to collect the streambed data. In future work, volunteers should simply conduct a visual assessment of the streambed habitat with respect to sediment [16]. By increasing the number of cross-sections analyzed per group a project such as this could then use statistics to test a null hypothesis of no difference between the groups; this would allow other researchers to extrapolate the findings of what is now only a case study and be more confident in predicting the usefulness of volunteer-collected data.

Involving volunteers in watershed monitoring is often done fill to in data gaps for managers; as such, the data should continue to be scrutinized, and new methods should be developed to increase both precision and accuracy. However, many other benefits come from incorporation volunteers in watershed modeling; volunteers have been shown to become more politically active, to increase their personal networks, and to feel more connected to their communities [32]. The middle school students thoroughly enjoyed the fieldwork and took it quite seriously because they knew they were collecting real data that would be used by environmental managers. However, it was the parent volunteers who were the most surprising. Many of them had grown up in the Fairview Creek watershed and yet they had never really spent much time near the actual stream. The several hours collecting data and making observations left them feeling that this urban stream was much more wild than they had imagined, and many of them inquired about getting involved with a local watershed council. Thus, these community volunteers represent both the best opportunity to collect badly needed environmental data and the champions of implementing watershed scale restoration.

\section{Acknowledgments}

This project could not have been done without the assistance of the Walt Morey Middle School sixth grade teachers Michelle O'Brien and Christina Barber-Lafrenz as well as graduate research assistant, Stephanie Gaspers. A very special thanks goes out to all the sixth grade students, the Portland State students, and the parent volunteers who contributed their time and effort to this project. This research was partially funded by a Portland State University Faculty enhancement grant and was greatly improved by comments from anonymous reviewers.

\section{References}

[1] J. G. Arnold, R. Srinivasan, R. S. Muttiah, and J. R. Williams, "Large area hydrologic modeling and assessment part I: model development," Journal of the American Water Resources Association, vol. 34, no. 1, pp. 73-89, 1998.

[2] V. P. Singh and D. K. Frevert, Eds., Mathematical Models of Small Watershed Hydrology and Applications, Water Resources, Highlands Ranch, Colo, USA, 2002.

[3] C. J. Walsh, A. H. Roy, J. W. Feminella, P. D. Cottingham, P. M. Groffman, and R. P. Morgan II, “The urban stream syndrome: current knowledge and the search for a cure," Journal of the North American Benthological Society, vol. 24, no. 3, pp. 706723, 2005.

[4] D. K. Borah and M. Bera, "Watershed-scale hydrologic and nonpoint-source pollution models: review of mathematical bases," Transactions of the American Society of Agricultural Engineers, vol. 46, no. 6, pp. 1553-1566, 2003.

[5] A. Simon, A. Curini, S. E. Darby, and E. J. Langendoen, "Bank and near-bank processes in an incised channel," Geomorphology, vol. 35, no. 3-4, pp. 193-217, 2000.

[6] C. D. Willett, R. N. Lerch, R. C. Schultz, S. A. Berges, R. D. Peacher, and T. M. Isenhart, "Streambank erosion in two watersheds of the central claypan region of Missouri, United States," Journal of Soil and Water Conservation, vol. 67, no. 4, pp. 249-263, 2012.

[7] S. J. Bennett, A. Simon, J. M. Castro et al., "The evoloving science of stream restoration," in Stream Restoration in Dynamic Fluvial Systems, A. Simon, S. J. Bennett, and J. M. Castro, Eds., vol. 194 of Geophysical Monograph Series, pp. 1-8, American Geophysical Union, Washington, DC, USA, 2013.

[8] Federal Interagency Stream Restoration Working Group, "Stream Corridor Restoration: Principles, Processes, and Practices," GPO Item no. 0120-A, SuDocs no. A 57. 6/2:EN 3/PT. 653, 1998.

[9] S. Heiskary, J. Lindbloom, and C. B. Wilson, "Detecting water quality trends with citizen volunteer data," Lake and Reservoir Management, vol. 9, no. 1, pp. 4-9, 1994.

[10] M. D. Mattson, M. F. Walk, P. A. Kerr, A. M. Slepskie, O. T. Zajicek, and P. J. Godfrey, "Quality assurance testing for a large 
scale volunteer monitoring program: the acid rain monitoring project," Lake and Reservoir Management, vol. 9, no. 1, pp. 10-13, 1994.

[11] J. V. Loperfido, P. Beyer, C. L. Just, and J. L. Schnoor, "Uses and biases of volunteer water quality data," Environmental Science and Technology, vol. 44, no. 19, pp. 7193-7199, 2010.

[12] S. R. Engel, J. R. Voshell, and Jr, "Volunteer biological monitoring: can it accurately assess the ecological condition of streams?" American Entomologist, vol. 48, no. 3, pp. 164-177, 2002.

[13] J. F. Nerbonne and K. C. Nelson, "Volunteer macroinvertebrate monitoring in the United States: resource mobilization and comparative state structures," Society and Natural Resources, vol. 17, no. 9, pp. 817-839, 2004.

[14] L. S. Fore, K. Paulsen, and K. O'Laughlin, "Assessing the performance of volunteers in monitoring streams," Freshwater Biology, vol. 46, no. 1, pp. 109-123, 2001.

[15] E. Nicholson, J. Ryan, and D. Hodgkins, "Community datawhere does the value lie? Assessing confidence limits of community collected water quality data," Water Science and Technology, vol. 45, no. 11, pp. 193-200, 2002.

[16] United States Environmental Protection Agency, "Volunteer stream monitoring: a methods manual," Tech. Rep., Office of Water 4503F, Washington, DC, USA, EPA 841-B-97-003, 1997.

[17] M. Kline, C. Alexander, S. Pomeroy, B. Cahoon, and L. Becker, Vermont Stream Geomorphic Assessment Phase 2 Handbook, Vermont Agency of Natural Resources, Montpelier, Vt, USA, 2004.

[18] M. B. . Bain and N. J. Steveson, Eds., Aquatic Habitat Assessment: Common Methods, American Fisheries Society, Bethesda, Md, USA, 1999.

[19] D. R. Montgomery and J. M. Buffington, "Channel-reach morphology in mountain drainage basins," Bulletin of the Geological Society of America, vol. 109, no. 5, pp. 596-611, 1997.

[20] J. Meyer and J. Wallace, "Lost linkages and lotic ecology: rediscovering small streams," in Ecology: Achievement and Challenge., M. Press, N. Huntly, and S. Levin, Eds., pp. 295-317, Blackwell Scientific, Oxford, UK, 2001.

[21] T. Gomi, R. D. Moore, and A. S. Dhakal, "Headwater stream temperature response to clear-cut harvesting with different riparian treatments, coastal British Columbia, Canada," Water Resources Research, vol. 42, no. 8, 2006.

[22] R. C. Ward, "On the response to precipitation of headwater streams in humid areas," Journal of Hydrology, vol. 74, no. 1-2, pp. 171-189, 1984.

[23] E. J. Nelson and D. B. Booth, "Sediment sources in an urbanizing, mixed land-use watershed," Journal of Hydrology, vol. 264, no. 1-4, pp. 51-68, 2002.

[24] J. Poracsky, J. Holland, and J. Wilt, "An inventory of nine stream corridors in multnomah county," Oregon Cartographic Center, Geography Department, Portland State University, 1990.

[25] C. C. Harrelson, C. L. Rawlins, and J. P. Potyondy, "Stream channel reference sites: an Illustrated guide to field technique," General Technical Report RM-245, Forest Service, Rocky Mountain Forest and Range Experiment Station, Fort Collins, Colo, USA, 1994.

[26] M. G. Wolman, "A method of sampling coarse river-bed material," Transactions of the American Geophysical Union, vol. 35, no. 6, pp. 951-956, 1954.

[27] "Quorer: a simple methodfor estimating deposited fine sediment," National Center for Water Resources, 2005, http://www .niwascience.co.nz/ncwr/tools/quorer/index.html.
[28] S. A. Schumm, The Fluvial System, John Wiley \& Sons, New York, NY, USA, 1977.

[29] "US Geological Survey," The StreamStats program, 2013, http: //streamstats.usgs.gov.

[30] K. Bunte, S. Abt, and R. Steven, "Sampling surface and subsurface particle-size distributions in wadable gravel-and cobblebed streams for analyses in sediment transport, hydraulics, and streambed monitoring," General Technical Report RMRSGTR-74, United States Department of Agriculture, Forest Service, Fort Collins, Colo, USA, 2001.

[31] M. A. Fonstad, J. P. Reichling, and J. W. Van de Grift, “The transparent velocity-head rod for inexpensive and accurate measurement of stream velocities," Journal of Geoscience Education, vol. 53, no. 1, pp. 44-52, 2005.

[32] C. Overdevest, C. H. Orr, and K. Stepenuck, "Volunteer stream monitoring and local participation in natural resource issues," Human Ecology Review, vol. 11, no. 2, pp. 177-185, 2004. 

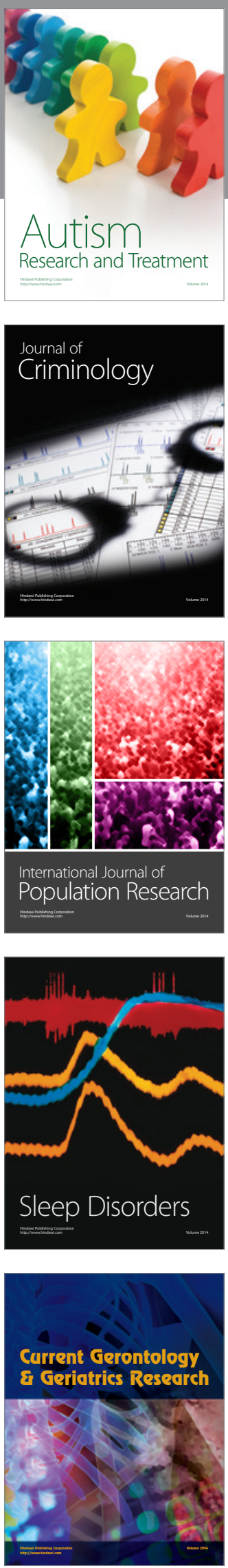
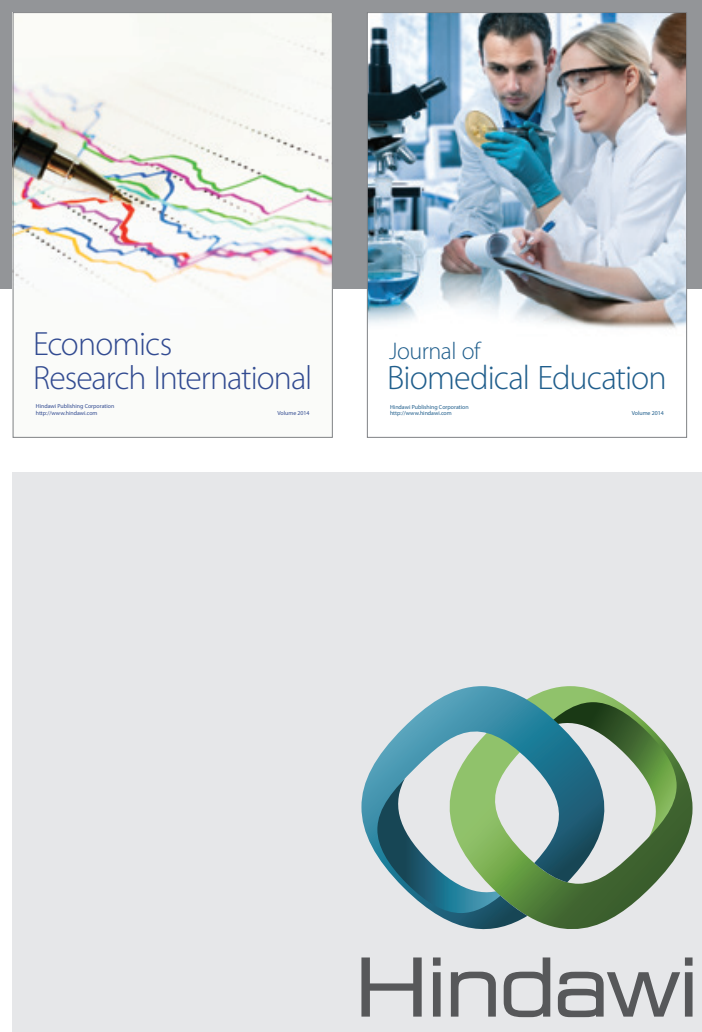

Submit your manuscripts at

http://www.hindawi.com
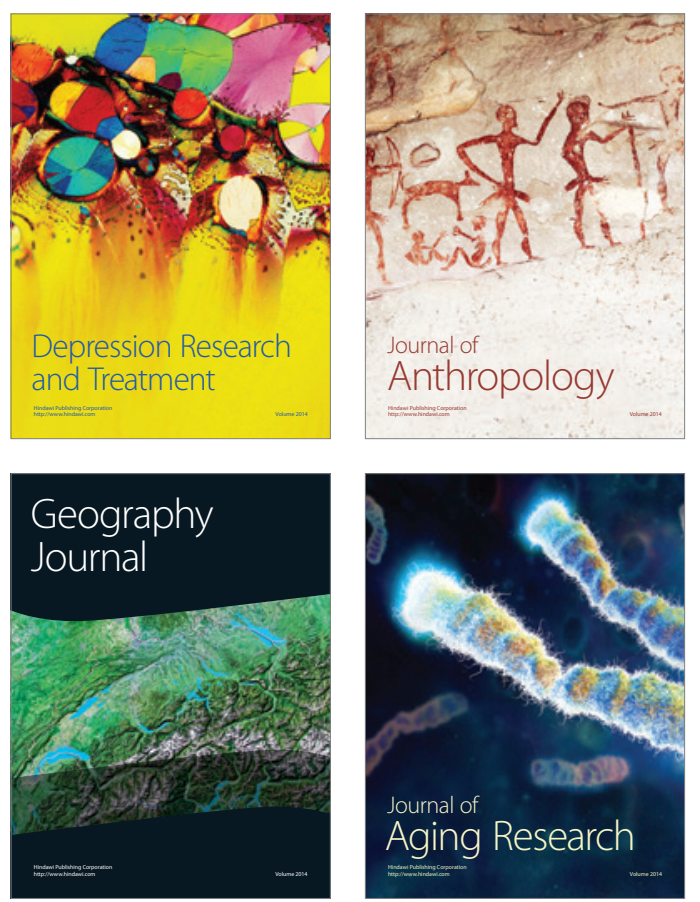
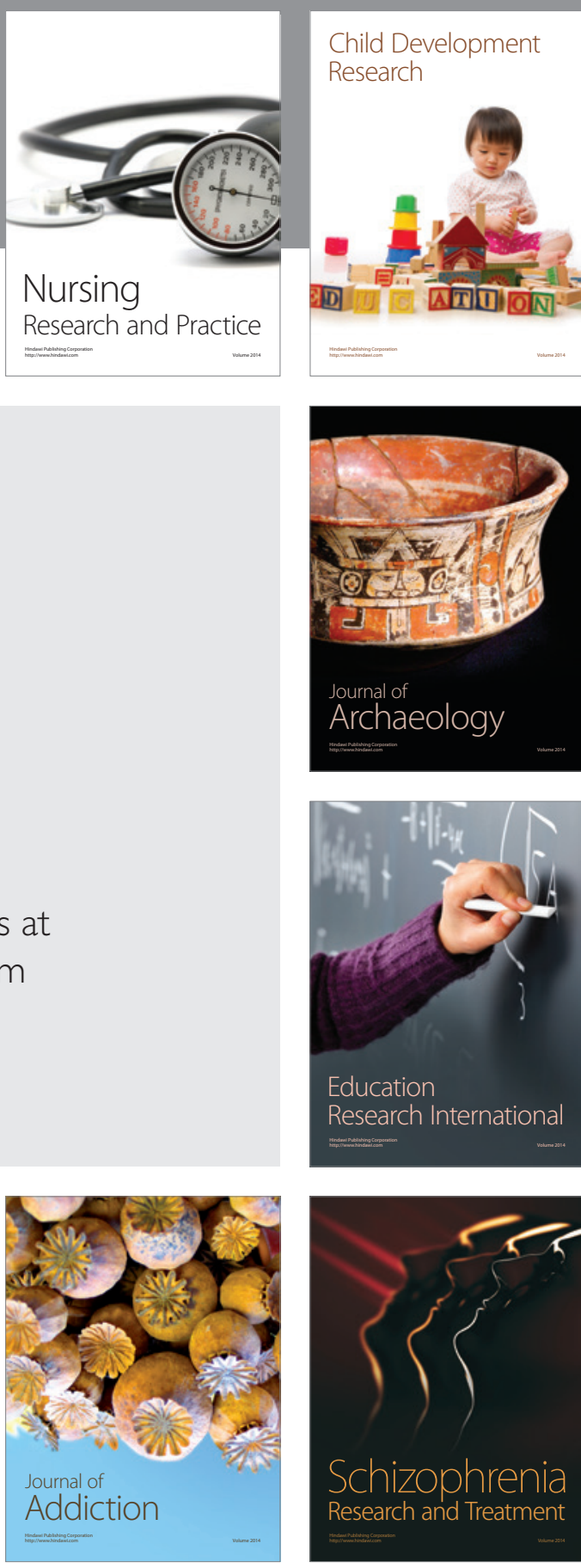

(D)
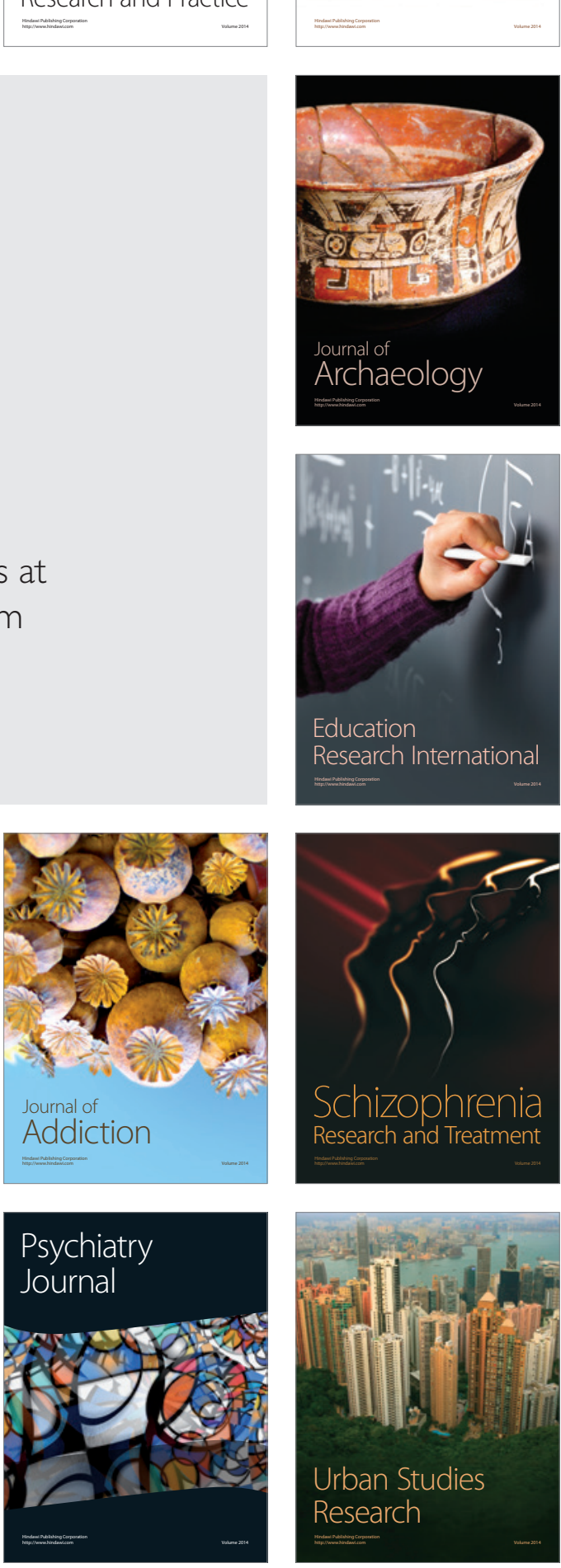